\title{
Geographic Information System-Based Mobile Application Design for Health Care in Older Persons in Rural Community by Village Health Volunteers
}

\author{
Kukiat TUDPOR ${ }^{\mathrm{a}, \mathrm{b}}$, Adisorn WONGKONGDECH ${ }^{\mathrm{a}}$, Ranee WONGKONGDECH ${ }^{\mathrm{c}}$, \\ Thanyarat CHAIYAKARM ${ }^{\mathrm{d}}$, Worawit JITSUKKA ${ }^{\mathrm{d}}$, Kemika SOMBATEYOTHA ${ }^{\mathrm{a}}$, \\ Songkramchai LEETHONGDEESAKUL ${ }^{\mathrm{a}}$, Narongsakdi KUBOONYA-ARAGSA ${ }^{\mathrm{e}}$, \\ Chalard CHANTARSOMBAT ${ }^{\mathrm{f}}$, Krissanachai KIMCHAI ${ }^{\mathrm{g}}$, Nutchanun \\ KAMONROEK $^{\mathrm{h}}$ and Niruwan TURNBULL ${ }^{\mathrm{a}, \mathrm{b}, 1}$ \\ ${ }^{a}$ Faculty of Public Health, Mahasarakham University, Thailand \\ ${ }^{\mathrm{b}}$ Public Health and Environmental Policy in Southeast Asia Research Unit \\ (PHEP-SEA), Mahasarakham University, Thailand \\ ${ }^{\mathrm{c}}$ Faculty of Medicine, Mahasarakham University, Thailand \\ ${ }^{\mathrm{d}}$ Faculty of Humanities and Social Sciences, Mahasarakham University, Thailand \\ e Department of Labour Protection and Welfare, Ministry of Labour, Thailand \\ ${ }^{\mathrm{f}}$ Faculty of Education, North Eastern University, Thailand \\ ${ }^{g}$ Northeasthern Regional Center for Primary Health Care Development, Thailand

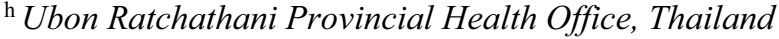

\begin{abstract}
Health care for older persons is important for their well-being. In Thailand, village health volunteers (VHVs) play a crucial role in communicating between the older persons and health care professionals. Traditionally, they record and submit a monthly report as papers. This project was aimed to design a geographical information system (GIS)-based mobile application for health care in older persons in rural community by the VHVs. As a part of the analysis, design, development, implementation, and evaluation (ADDIE) model, health information obtained from 8,348 older persons and 1,125 VHVs living in rural community were analyzed and used for the for iPhone (iOS) and Android devices, and web browser. In summary, this mobile application allows the VHVs locate the older person's addresses and communicate with health care staff online in time-saving manner.
\end{abstract}

Keywords. Geographic information system, Mobile application, Older persons, Health care

\section{Introduction}

World's older population is drastically growing. Based on data from an Office of the National Economic and Social Development Council (NESDC), Thailand is considered as an aged society in 2021 since its elderly population has reached 18.7 percent of the

${ }^{1}$ Corresponding author, Niruwan Turnbull, Faculty of Public Health, Mahasarakham University, Kham Rieng, Kantharawichai, Maha Sarakham, Thailand 44150; E-mail: niruwan.o@msu.ac.th 
total population $(1,2)$. Older persons have are prone to multiple age-related changes such as tissue and organ simultaneous degeneration, increased sensitivity to diseases and environmental stressors (3). Therefore, continuous monitoring of health and diseases are crucial for efficient health care services. However, most of older persons in Northeastern part of Thailand live in rural areas faraway from health care facilities. Subdistrict Health Promotion Hospital (SHPH) system has been a key unit providing primary health care for people living in rural areas of Thailand. In close relationship with the SHPH, village health volunteers (VHVs) play a pivotal role in primary care system. Their tasks are to provide health screening, self-care advice, basic health care, and communication between villagers and hospitals. Normally, VHVs have to submit data to the hospital information center on monthly basis by papers or online, depending on policies of the local SHPH. This present project was aimed to demonstrate a designing process of a GISbased mobile application for health care in rural community-dwelling older persons by the VHVs.

\section{Methods}

\subsection{Informants and data collection}

As a part of the analysis, design, development, implementation, and evaluation (ADDIE) model in the project "Development of Mobile Application of Database of Older Persons Using Geographic Information System (GIS) to Detect and Analyze Risks of Chronic Diseases, Quality of Life, and Mental Illness by Village Health Volunteers in $7^{\text {th }}$ Regional Health Office Territory, (VHVA)", all older persons $(\mathrm{N}=8,348)$ and all VHVs $(\mathrm{N}=1,125)$ were from 8 subdistricts in 4 provinces. Inclusion criteria of the older persons were age $\geq 60$ years old and signed consent form. The older adults not physically present in the areas during the survey were excluded. All procedures have been conducted in accordance with the Declaration of Helsinki and approved by the Ethical Review Committee for Human Research, Maha Sarakham Provincial Public Health Office (No.6/2564). Partial socio-demographic profiles of the elders are presented in Table 1.

Table 1. Socio-demographic profiles of the older persons $(\mathrm{N}=8,348)$

\begin{tabular}{llc}
\hline \multicolumn{1}{c}{ Profile } & \multicolumn{1}{c}{ Category } & n (\%) \\
\hline Gender & Male & $3,587(42.97)$ \\
& Female & $4,757(56.98)$ \\
Age & LGBT & $4(0.05)$ \\
& $60-69$ & $4,597(55.07)$ \\
Marital status & $\geq 70$ & $3,751(44.93)$ \\
& Married & $5,353(64.12)$ \\
Living arrangement & Single (widowed/divorced/separate) & $2,995(35.88)$ \\
& Living with family & $7,869(94.26)$ \\
Educational level & Living alone & $479(5.74)$ \\
& Higher than primary school & $615(7.37)$ \\
Occupational status & Primary school or no schooling & $7,733(92.63)$ \\
& Working & $5,899(70.66)$ \\
Economic status & Not working & $2,449(29.34)$ \\
& Enough income for living & $2,912(34.88)$ \\
Activities of daily living (ADL) level & Not enough income for living & $5,436(65.12)$ \\
& Independent & $8,122(97.29)$ \\
Non-communicable disease (NCD) & Dependent & $226(2.71)$ \\
& No hypertension or diabetes mellitus & $4,487(53.74)$ \\
& Hypertension or diabetes mellitus & $3,861(46.26)$ \\
\hline
\end{tabular}




\subsection{Application design}

The mobile application was built up with the Apache Cordova ${ }^{\mathrm{TM}}$ platform for both iOS and Android devices. The Google Map Application Programming Interface (API) was used by the web administrator to view and share latitude and longitude. After deployment, the app runs in the web browser. Only authorized web administrator had an access to the encrypted server. Data exports and printouts can be obtained by SHPH staff with secured passwords.

\section{Results}

\subsection{User interface}

Information of older persons collected by the VHVs on mobile was managed by the web admin. Examples of user interface shown in Figure 1 consists of 1) login page, 2) menus (purple, health assessment; orange, knowledge resources; green, home visit; and red, emergency call), and 3) location search page. SHPH staff were able to double check information and provide feedback.

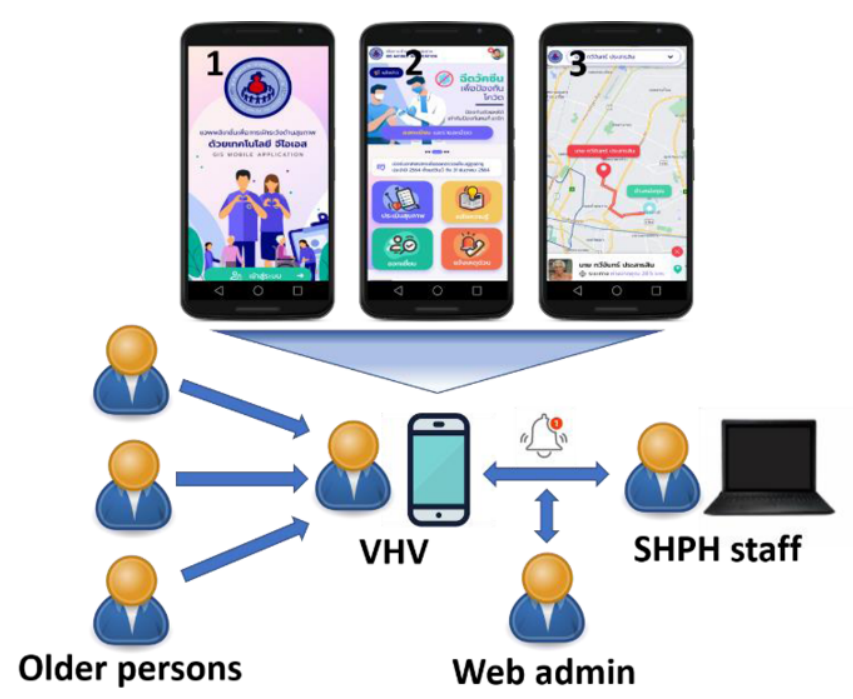

Figure 1. Mobile application information flow and screen displays

Table 2. Outcome measures and data collection tools for the mobile application

\begin{tabular}{ll}
\hline \multicolumn{1}{c}{ Outcome measure } & \multicolumn{1}{c}{ Data collection tools } \\
\hline Geographic coordinate & Global navigation satellite system (GNSS) and GIS programs \\
Health screening and medical record & Secondary data from SHPH \\
$\begin{array}{l}\text { Psychological stress level } \\
\text { Quality of life (QOL) }\end{array}$ & Newly validated questionnaire \\
& World Health Organization Quality of Life for Older Persons \\
$\begin{array}{ll}\text { Activities of daily living (ADLs) } \\
\text { Knowledge, attitude, and practice } \\
\text { (KAP) on health care }\end{array}$ & Barthel Index for Activities of Daily Living questionnaire \\
\hline
\end{tabular}




\subsection{Outcome measures and data collection tools}

This mobile application contained 6 outcome measures and data collection tools for VHVs and local heal care staff: geographic coordinate, health screening and medical history, psychological stress level, QOL, ADLs, and KAP on health care (Table 2).

\section{Discussion}

\subsection{GIS-based mobile applications for health care in older persons}

More than 2,000 mobile health applications for older person were invented, but none were designed for dependent older persons (4). Our application was designed for both dependent and independent groups and was the first GIS-based mobile application for health care in older persons by the VHVs in Thailand. The GIS has been proved as an efficient and travel-time saving tool for people living in remote areas (5).

\subsection{User interface and utilities}

Our mobile application design was based on user requirements. GIS applications can be divided into 4 themes: health surveillance, support, promotion and prevention; and communication among health care staff (6). Our application served all of these aspects. Limitation of the project was a gap of communication between the design team and the VHVs and the older persons during COVID-19 pandemic; and telecommunication was applied in substitute for face-to-face contact.

\section{Conclusion}

In conclusion, the GIS-based mobile application for health care in older persons living in rural community of Thailand by the VHVs has been designed. The application will be further developed, implemented, evaluated based on feedback from the users.

\section{References}

[1] Khamken PW. Sufficiency Economy Philosophy Towards Poverty Eradication in Thailand. Psychology and Education Journal. 2021;58(1):1406-11.

[2] Lee SB, Oh JH, Park JH, Choi SP, Wee JH. Differences in youngest-old, middle-old, and oldest-old patients who visit the emergency department. Clin Exp Emerg Med. 2018;5(4):249-55.

[3] Nigam Y, Knight J, Bhattacharya S, Bayer A. Physiological changes associated with aging and immobility. J Aging Res. 2012;2012:468469.

[4] Paiva JOV, Andrade RMC, de Oliveira PAM, Duarte P, Santos IS, Evangelista ALP, et al. Mobile applications for elderly healthcare: A systematic mapping. PLoS One. 2020;15(7):e0236091.

[5] Weiss DJ, Nelson A, Vargas-Ruiz CA, Gligoric K, Bavadekar S, Gabrilovich E, et al. Global maps of travel time to healthcare facilities. Nat Med. 2020;26(12):1835-8.

[6] Nhavoto JA, Gronlund A. Mobile technologies and geographic information systems to improve health care systems: a literature review. JMIR Mhealth Uhealth. 2014;2(2):e21. 